\title{
Contrast of diagnostic value between IL-17 combined with IL-18 and CT angiography in carotid atherosclerosis
}

\author{
FENG SUO $^{1 *}$, FEI JIANG ${ }^{1 *}$, XIUHONG FANG ${ }^{1}$, AIHUA MA $^{2}$ and LIPING MA ${ }^{3}$ \\ ${ }^{1}$ Department of Radiology, People's Hospital of Dongying, Dongying, Shandong 257091; \\ ${ }^{2}$ Pharmacy Intravenous Admixture Services and ${ }^{3}$ Department of Science and Education, \\ The People's Hospital of Zhangqiu Area, Zhangqiu, Shandong 250200, P.R. China
}

Received May 25, 2018; Accepted November 30, 2018

DOI: $10.3892 /$ etm.2018.7088

\begin{abstract}
Diagnostic value between IL-17 combined with IL-18 and CT angiography in carotid atherosclerosis was evaluated. A total of 158 patients with suspected carotid artery stenosis in People's Hospital of Dongying from March 2014 to April 2017 were selected as the subjects. One hundred and two patients with carotid atherosclerosis were selected as the atherosclerosis group, the other 56 patients with no obvious carotid artery abnormalities were selected as the disease control group. In addition, there were 100 healthy subjects selected as the healthy control group. The level of IL-17 and IL-18 in peripheral blood of all the subjects was detected by ELISA. The ROC curve was used to analyze the diagnostic value of IL-17 combined with IL-18 and CT angiography in atherosclerosis. The levels of IL-17 and IL-18 in the three groups were different $(\mathrm{P}<0.05)$. The level of IL-17 and IL-18 in the atherosclerosis and disease control groups was higher than that in the healthy control group, and the level of IL-17 and IL-18 in the atherosclerosis was higher than that in the disease control group. The sensitivity of IL-17 or IL-18 was less than the coincidence rate and sensitivity of IL-17 combined with IL-18 as diagnostic criteria, and AUC was also less than AUC of IL-17 combined with IL-18. The sensitivity and diagnostic accuracy of IL-17 combined with IL-18 in the diagnosis of carotid atherosclerosis were not significantly different from CT angiography $(\mathrm{P}>0.05)$, but the specificity was obviously lower than $\mathrm{CT}$ angiography $(\mathrm{P}<0.05)$. The diagnosis of atherosclerosis of IL-17 combined with IL-18 was more accurate, it can improve the diagnostic efficiency of atherosclerosis and be used as a routine method for screening the atherosclerosis.
\end{abstract}

Correspondence to: Dr Feng Suo, Department of Radiology, People's Hospital of Dongying, 317 Dongcheng South First Road, Dongying, Shandong 257091, P.R. China

E-mail:sol8dw@163.com

"Contributed equally

Key words: IL-17 combined with IL-18, CT angiography, carotid atherosclerosis, diagnostic value

\section{Introduction}

Carotid atherosclerosis is a very common disease in cardiovascular medicine, and it is the basis of cerebral vascular disease such as stroke. There are approximately sixty percent stroke patients related to it. It is one of the main causes of death worldwide $(1,2)$. It is reported that the incidence of carotid atherosclerosis has declined in developed countries in recent years, while increased in developing countries, which may result from dietary patterns changing caused by economic development, because high-fat diet and low-cholesterol consumption play a very important role in the pathogenesis of carotid atherosclerosis $(3,4)$.

Among non-invasive examination methods, CT angiography is a widely used method in the diagnosis of carotid and cervical atherosclerosis. It is a popular technique for diagnosis of carotid atherosclerosis as it is fast, convenient, repeatable and its temporal resolution is high $(5,6)$. However, CT angiography is not suitable for all patients. It is closely related to the heart rate and blood flow status of the patient. The slow flow of blood may cause inadequate imaging, and the CT angiography cannot be used in patients with contrast agent. It is closely related to the heart rate $(7,8)$. In recent years, the diagnosis of serology and the diagnosis of molecular biology are very popular directions of study. IL-17 and IL-18 are two molecules associated with atherosclerosis. It is reported that the level of IL-17 protein and mRNA in the peripheral blood of patients with acute coronary syndrome is significantly higher than that of healthy subjects (9). IL-18 can induce the expression of $\gamma$ interferon, a proinflammatory cytokine, which is reported to be involved in the rupture of atherosclerotic plaques (10). Therefore, we speculate that IL-17 and IL-18 have the diagnosis value of carotid atherosclerosis.

In this study, we compared and analyzed the diagnostic value of IL-17 combined with IL-18 and CT angiography in 158 patients with suspected carotid artery stenosis in order to provide a reference for the clinical diagnosis of carotid atherosclerosis.

\section{Materials and methods}

Clinical data. From March 2014 to April 2017 in People's Hospital of Dongying (Dongying, China), 158 patients with 
suspected carotid stenosis were selected as the subjects. One hundred and two patients with carotid atherosclerosis were selected as the atherosclerosis group. The other 56 patients with no obvious carotid artery abnormalities were selected as the disease control group, and there were 100 healthy subjects selected in the same period after health examination as the healthy control group. Carotid atherosclerosis conforms to the diagnostic standard of International Atherosclerosis Society (11), which included patients with suspected ischemic cerebrovascular disease with or without clinical symptoms, and excluded patients with carotid stenosis caused by arterial dissection, patients with stable vital signs, no obvious contraindication, and patients with coronary heart disease, patients with intermittent myocardial infarction, patients with acute myocardial infarction, patients with cerebral atherosclerosis, patients with infectious disease, patients with severe cardiac insufficiency, tumor patients, patients with grade III hypertension, patients with liver and kidney failure, patients with incomplete case information, and patients with mental or learning disability. The control group underwent physical examination to exclude organic diseases and Alzheimer's disease. This study was approved by the Ethics Committee of People's Hospital of Dongying, and the patients or their family members signed an informed consent.

ELISA detection of IL-17 and IL-18. The levels of IL-17 and IL-18 in peripheral blood of three groups of patients were detected, and the peripheral blood of patients in the morning under fasting condition was collected by nurses in People's Hospital of Dongying. IL-17 test kit was purchased from R\&D Systems, Inc. (Minneapolis, MN, USA) and IL-18 test kit was purchased from Beijing Keyingmei Technology (Beijing, China). ELISA was used to determine the level of IL-17 and IL-18 in the samples. First, the standard curve of IL-17 and IL-18 was established, then blank, standard and sample wells were set up, and standard sample was added to enzyme labeled well precoated with primary IL-17 or IL-18 monoclonal antibody (dilution, 1:300; cat. nos. HS750, D8000C; R\&D Systems, Inc.) followed by incubation at $37^{\circ} \mathrm{C}$ for $30 \mathrm{~min}$. After washing, horseradish peroxidase labeled IL-17 or IL-18 antibodies were added. After incubation at $37^{\circ} \mathrm{C}$ for $30 \mathrm{~min}$, the unbound enzyme was removed, then the substrate was added to show color at room temperature without light. In $15 \mathrm{~min}$, the absorbance value (OD value) of each well at $450 \mathrm{~nm}$ wavelength was read under the blank well, and the amount of OD value was positively correlated with the concentration of IL-17 or IL-18 in the sample. Three groups of repeated wells were set up, and the experiment was repeated 3 times.

CT angiography. CT angiography was performed in the atherosclerosis and disease control groups. The scanning equipment was GE Company Light Speed VCT (GE Healthcare, Milwaukee, WI, USA). The scan ranges from the arterial arch to the upper edge of the external auricle. The first sequence is plain scanning, and the second sequence is enhancement scanning with unchangeable parameters. Scanning parameters: voltage $120 \mathrm{KV}$, current 300-500 mA, detector width $128 \mathrm{~mm} \times 0.625 \mathrm{~mm}$, layer thickness $0.9 \mathrm{~mm}$, layer spacing $0.5 \mathrm{~mm}$, alignment $0.625 \mathrm{~mm}$, FOV $180 \mathrm{~mm}$, screw pitch 0.984 , spherical tube rotation speed $0.5 \mathrm{sec} /$ rot.
Table I. Comparison of the basic data.

\begin{tabular}{|c|c|c|c|c|c|}
\hline Factors & $\begin{array}{l}\text { Atherosclerosis } \\
\text { group }\end{array}$ & $\begin{array}{c}\text { Disease } \\
\text { control } \\
\text { group }\end{array}$ & $\begin{array}{l}\text { Healthy } \\
\text { control } \\
\text { group }\end{array}$ & $\mathrm{F} / \chi^{2}$ & P-value \\
\hline No. of patients & 102 & 56 & 100 & & \\
\hline Male/female & $72 / 30$ & $32 / 24$ & $52 / 48$ & 2.629 & 0.302 \\
\hline Age (years) & $52.5 \pm 11.4$ & $54.6 \pm 12.5$ & $49.7 \pm 13.3$ & 3.028 & 0.050 \\
\hline $\begin{array}{l}\text { Hypertension } \\
(\mathrm{n}, \%)\end{array}$ & $82(80.4)$ & $10(17.9)$ & & 58.125 & $5<0.001$ \\
\hline $\begin{array}{l}\text { Hyperlipidemia } \\
(\mathrm{n}, \%)\end{array}$ & $86(84.3)$ & $14(25.0)$ & & 54.743 & $3<0.001$ \\
\hline Diabetes (n, \%) & $32(31.4)$ & $5(8.9)$ & & 10.154 & 0.001 \\
\hline $\begin{array}{l}\text { Weight (n, \%) } \\
\geq 60 \mathrm{~kg} \\
<60 \mathrm{~kg}\end{array}$ & $\begin{array}{l}63(61.8) \\
39(38.2)\end{array}$ & $\begin{array}{l}32(57.1) \\
24(42.9)\end{array}$ & $\begin{array}{l}59(59.0) \\
41(41.0)\end{array}$ & 0.353 & 0.828 \\
\hline $\begin{array}{l}\text { History of } \\
\text { smoking (n, \%) } \\
\text { Positive } \\
\text { Negative }\end{array}$ & $\begin{array}{l}52(51.0) \\
50(49.0)\end{array}$ & $\begin{array}{l}23(41.1) \\
33(58.9)\end{array}$ & $\begin{array}{l}43(43.0) \\
57(57.0)\end{array}$ & 2.097 & 0.351 \\
\hline $\begin{array}{l}\text { Exercise habits } \\
(\mathrm{n}, \%)\end{array}$ & & & & 2.329 & 0.312 \\
\hline Negative & $68(66.7)$ & $39(69.6)$ & $65(65.0)$ & & \\
\hline Positive & $34(33.3)$ & $17(30.4)$ & $35(35.0)$ & & \\
\hline
\end{tabular}

The nonionic contrast agent used for the VCT examination was omnipaque produced by GE Pharmaceutical Co., Ltd. (Shanghai, China). By injection of the anterior elbow vein, the rate of 4-4.4 ml/sec, the quantitative injection of $60-80 \mathrm{ml}$, and then the addition of the physiological saline $40 \mathrm{ml}$, image processing technology is used to display lesions on AM4.4 workstation. Two experienced radiologists used double blind methods to diagnose the images respectively.

Statistical analysis. SPSS19.0 [AsiaAnalytics (formerly SPSS China), Shanghai, China] was used. Enumeration data were expressed in (n, \%), and $\chi^{2}$ test was used for comparison of the rates. The measurement data were expressed as mean \pm standard deviation. ANOVA was used for comparison among the multiple groups, and LSD test was used for comparison between the two groups. The receiver operating curve (ROC) was used to analyze the diagnostic value. $\mathrm{P}<0.05$ was considered to indicate a statistically significant difference.

\section{Results}

Clinical data. There were 158 cases of suspected carotid artery stenosis, among which 102 patients with carotid atherosclerosis in the atherosclerosis group, including 72 male and 30 female patients, with an average age of $52.5 \pm 11.4$ years and 56 patients in the disease control group, including 32 male and 24 female patients, with an average age of $54.6 \pm 12.5$ years. There were 100 healthy subjects in the healthy control group, including 52 males and 48 females, with an average age of $49.7 \pm 13.3$ years. There was no significant difference among the three groups in basic data such as weight, age, sex, smoking history and exercise habits $(\mathrm{P}>0.05)$. The proportion 
Table II. The results of IL-17 and IL-18 test.

\begin{tabular}{|c|c|c|c|c|c|}
\hline Factors & Atherosclerosis group & Disease control group & Healthy control group & F-value & P-value \\
\hline No. of patients & 102 & 56 & 100 & & \\
\hline IL-17 (ng/l) & $30.35 \pm 5.12$ & $21.12 \pm 3.33^{\mathrm{a}}$ & $10.32 \pm 2.45^{\mathrm{a}, \mathrm{b}}$ & 674.867 & $<0.001$ \\
\hline IL-18 (ng/ml) & $336.5 \pm 132.5$ & $214.7 \pm 58.9^{\mathrm{a}, \mathrm{b}}$ & $114.9 \pm 30.6^{\mathrm{a}, \mathrm{b}}$ & 154.326 & $<0.001$ \\
\hline
\end{tabular}

${ }^{\mathrm{a}} \mathrm{P}<0.05$, compared with the atherosclerosis group. ${ }^{\mathrm{b}} \mathrm{P}<0.05$, compared with the disease control group.

A

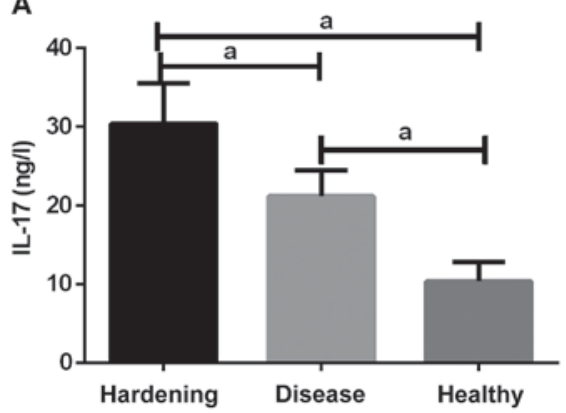

B

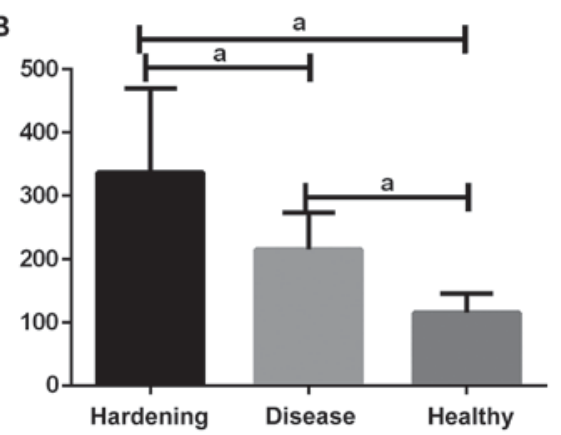

Figure 1. (A) The results of IL-17 test. The levels of IL-17 in the three groups were all different; the levels of IL-17 in the atherosclerosis and disease control groups were higher than those in the healthy control group ( $\left.{ }^{\mathrm{a}} \mathrm{P}<0.05\right)$, and the level of IL-17 in the atherosclerosis group was higher than that in the disease control group ( $\left.{ }^{\mathrm{a}} \mathrm{P}<0.05\right)$. (B) The results of IL-18 test. The levels of IL-18 in the three groups were all different; the levels of IL-18 in the atherosclerosis and disease control groups were higher than those in the healthy control group $\left({ }^{a} \mathrm{P}<0.05\right)$, and the level of IL-18 in the atherosclerosis group was higher than that in the disease control group $\left({ }^{a} \mathrm{P}<0.05\right)$.

Table III. Analysis of diagnostic value of IL-17 and IL-18 for carotid atherosclerosis.

\begin{tabular}{|c|c|c|c|c|}
\hline Factors & IL-17 & IL-18 & IL-17 combined with IL-18 & CT angiography \\
\hline AUC & 0.912 & 0.750 & 0.931 & \\
\hline $95 \%$ confidence interval & $0.870-0.954$ & $0.674-0.823$ & $0.893-0.968$ & \\
\hline Diagnostic standard & $13.45 \mathrm{ng} / 1$ & $279.5 \mathrm{ng} / \mathrm{ml}$ & & \\
\hline Sensitivity $(\%, \mathrm{n})$ & $68.6(70)$ & $62.7(64)$ & $77.5(79)^{\mathrm{a}}$ & $73.5(75)^{\mathrm{a}}$ \\
\hline Specificity $(\%, n)$ & $87.5(49)$ & $85.7(48)$ & $82.1(46)$ & $94.6(53)^{\mathrm{b}}$ \\
\hline Diagnostic coincidence rate $(\%, \mathrm{n})$ & $75.3(119)$ & $70.9(112)$ & $81.6(129)^{\mathrm{a}}$ & $81.0(128)^{\mathrm{a}}$ \\
\hline
\end{tabular}

${ }^{\mathrm{a}} \mathrm{P}<0.05$, compared with IL-17 and IL-18 for each. ${ }^{\mathrm{b}} \mathrm{P}<0.05$, compared with IL-17 and IL-18 and IL-17 combined with IL-18 for each.

of patients with hypertension, hyperlipidemia and diabetes in the atherosclerosis group was significantly higher than that in the disease control group $(\mathrm{P}<0.05)$ (Table I).

Detection results of $I L-17$ and $I L-18$. The results of IL-17 and IL-18 test detected by ELISA in the three groups of patients showed that the levels of IL-17 and IL-18 in the three groups were all different. The levels of IL-17 and IL-18 in the atherosclerosis and disease control groups were higher than that in the healthy control group $(\mathrm{P}<0.05)$, and IL-17 and IL-18 levels in the atherosclerosis group were higher than those in the disease control group $(\mathrm{P}<0.05)$ (Table II; Fig. 1).

Analysis of diagnostic value of CT angiography, IL-17 and IL-18 in 158 patients with suspected carotid atherosclerosis. The coincidence rate and the sensitivity of carotid atherosclerosis diagnosed by diagnostic criteria of IL-17 and IL-18 were less than those diagnosed by the diagnostic criteria of IL-17 combined with IL-18 ( $\mathrm{P}<0.05)$, AUC was also less than AUC of IL-17 combined with IL-18 ( $\mathrm{P}>0.05)$, and there was no significant difference among the three groups in specificity $(\mathrm{P}>0.05)$. The sensitivity and diagnostic accuracy of IL-17 combined with IL-18 in the diagnosis of carotid atherosclerosis were not significantly different from CT angiography $(\mathrm{P}>0.05)$, but the specificity was significantly lower than $\mathrm{CT}$ angiography $(\mathrm{P}<0.05)$ (Table III; Fig. 2).

\section{Discussion}

Carotid atherosclerosis poses a serious threat to human health. Approximately $60 \%$ of stroke patients are associated with carotid atherosclerosis, with a high incidence and mortality 


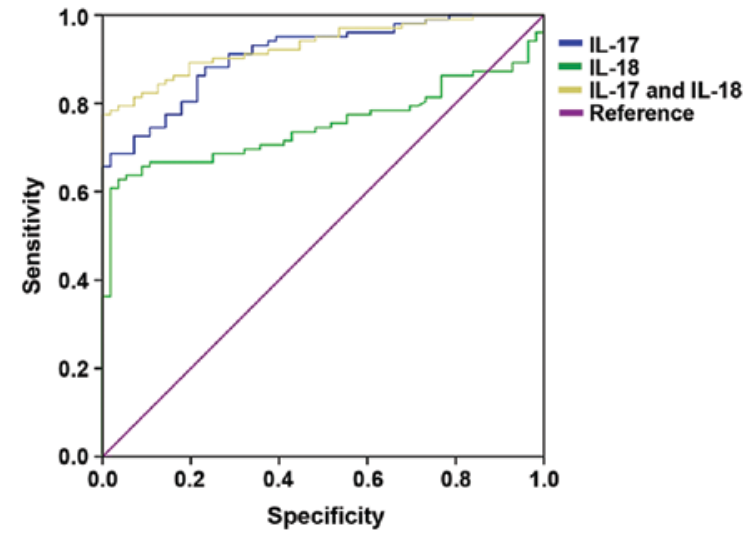

Figure 2. The ROC curves of IL-17 and IL-18 alone and IL-17 combined with IL-18 to diagnose carotid atherosclerosis. The coincidence rate and the sensitivity of carotid atherosclerosis diagnosed by diagnostic criteria of IL-17 and IL-18 were less than those diagnosed by the diagnostic criteria of IL-17 combined with IL-18 $(\mathrm{P}<0.05)$. AUC was also less than AUC of IL-17 combined with IL-18 ( $\mathrm{P}>0.05)$, and there was no significant difference among the three groups in specificity $(\mathrm{P}>0.05)$. AUC $($ IL-17) $=0.912$, AUC $($ IL-18) $=0.750$, AUC (IL-17 and IL-18) $=0.931$.

rate worldwide $(12,13)$. Therefore, accurate diagnosis of carotid atherosclerosis is very important in clinical treatment. Although the CT angiography is more economical than the whole brain angiography, the diagnostic coincidence rate is not ideal. Cerebral angiography is still needed even if CT angiography is used to detect the lesion, which is too expensive for many patients (14,15). IL-17 and IL-18 have an abnormal expression in the peripheral blood of atherosclerotic patients $(9,10)$. Therefore, the diagnostic value of IL-17 and IL-18 in the carotid artery is analyzed by detecting the level of IL-17 and IL-18 in the patients' serum, so as to provide help for the clinical diagnosis of carotid atherosclerosis.

This study analyzed the level of IL-17 and IL-18 in peripheral blood of 158 patients with suspected carotid artery stenosis, and the basic data such as age and sex in the three groups were not different, which suggested that the study has a certain credibility. The levels of IL-17 and IL-18 in the three groups were all statistically different. The level of IL-17 and IL-18 in the peripheral blood of 102 patients with carotid atherosclerosis were significantly higher than those in the disease control and healthy control groups. This may be related to the proportion of the three groups of patients with hypertension, hyperlipidemia and diabetes. The proportion of patients with hypertension, hyperlipidemia and diabetes in the atherosclerosis group were all higher than those in the disease control group, and the healthy control group excluded patients with hypertension, hyperlipidemia and diabetes. In many studies, the level of IL-17 and IL-18 in the peripheral blood of the patients with the three symptoms increased significantly (16-19). The elevated levels of IL-17 and IL-18 may also be associated with the rupture of atherosclerotic plaques. The rupture of the plaque caused vascular endothelial damage, the aggravation of the patient's inflammatory response and the increase of the level of IL-17 and IL-18 in the peripheral blood of the patients $(20,21)$. Therefore, IL-17 and IL-18 as a diagnostic molecule for carotid atherosclerosis have a certain feasibility. Therefore, we analyzed the diagnostic value of IL-17 and IL-18 in carotid atherosclerosis. The results of ROC analysis showed that diagnosing cervical arteriosclerosis by IL-17 alone, AUC was 0.912, the diagnostic level was $13.45 \mathrm{ng} / \mathrm{l}$, and the diagnostic coincidence rate, sensitivity and specificity were 75.3, 68.6 and 87.5\% respectively. Diagnosing cervical arteriosclerosis by IL-18 alone, AUC was 0.750 , the diagnostic level was $279.5 \mathrm{ng} / \mathrm{ml}$ and the diagnostic coincidence rate, sensitivity and specificity were $70.9,62.7$ and $85.7 \%$ respectively. The AUC, diagnostic coincidence rate and sensitivity diagnosed by IL-17 combined with IL-18 were all higher than the separate diagnosis, and the AUC was 0.931, with higher diagnostic value. Compared with CT angiography, although the specificity was significantly lower than CT angiography, the sensitivity and diagnostic coincidence rate of IL-17 combined with IL-18 in the diagnosis of carotid atherosclerosis were not significantly different from CT angiography. Therefore, it was feasible to detect carotid atherosclerosis by using the serological method to detect the levels of IL-17 and IL-18. It could be better to screen the carotid atherosclerosis, because its methodology is simple, and it has economic benefits with no adverse reactions, which is suitable for a wide range of individuals and will not create a physical or psychological burden to patients (22). There are few reports on IL-17 and IL-18 for the diagnosis of carotid atherosclerosis and few reports of IL-17 combined with IL-18 for the diagnosis of the disease. However, there are many more reports on the diagnosis of cancer by IL-17 and on the diagnosis of arthritis by IL-18, which both have a good value in the diagnosis of disease $(23,24)$. Therefore, the results of this study have a certain credibility, but more experimental studies are still needed to prove it. In addition, IL-17 and IL-18 may also have some defects in the diagnosis of carotid atherosclerosis. Carotid dissection is also an important cause of carotid stenosis. Due to the tear of the artery intima, the inflammatory reaction may also cause the increase of the levels of IL-17 and IL-18 $(25,26)$. Therefore, no patients with carotid artery dissection was included in this study. We hope that our study can induce more scholars to explore the molecular level on the diagnosis of carotid atherosclerosis.

In conclusion, IL-17 combined with IL-18 has a high diagnostic value for atherosclerosis, and can be used as a routine method for screening and diagnosing atherosclerosis.

\section{Acknowledgements}

Not applicable.

\section{Funding}

No funding was received.

\section{Availability of data and materials}

The datasets used and/or analyzed during the present study are available from the corresponding author on reasonable request.

\section{Authors' contributions}

FS and FJ performed ELISA. XF, AM and LM collected and analyzed the general data of patients. FS was responsible for CT angiography. All authors read and approved the final manuscript. 


\section{Ethics approval and consent to participate}

The study was approved by the Ethics Committee of People's Hospital of Dongying (Dongying, China). Patients who participated in this study, signed an informed consent and had complete clinical data.

\section{Patient consent for publication}

Not applicable.

\section{Competing interests}

The authors declare that they have no competing interests.

\section{References}

1. Baber U, Mehran R, Sartori S, Schoos MM, Sillesen H Muntendam P, Garcia MJ, Gregson J, Pocock S, Falk E, et al: Prevalence, impact, and predictive value of detecting subclinical coronary and carotid atherosclerosis in asymptomatic adults: The BioImage study. J Am Coll Cardiol 65: 1065-1074, 2015.

2. Pais R, Giral P, Khan JF, Rosenbaum D, Housset C, Poynard T and Ratziu V; LIDO Study Group: Fatty liver is an independent predictor of early carotid atherosclerosis. J Hepatol 65: 95-102, 2016.

3. Mutharasan RK, Thaxton CS, Berry J, Daviglus ML, Yuan C, Sun J, Ayers C, Lloyd-Jones DM and Wilkins JT: HDL efflux capacity, HDL particle size, and high-risk carotid atherosclerosis in a cohort of asymptomatic older adults: The Chicago Healthy Aging Study. J Lipid Res 58: 600-606, 2017.

4. Serban MC, Colantonio LD, Manthripragada AD, Monda KL, Bittner VA, Banach M, Chen L, Huang L, Dent R, Kent ST, et al: Statin intolerance and risk of coronary heart events and all-cause mortality following myocardial infarction. J Am Coll Cardiol 69: 1386-1395, 2017.

5. Nørgaard BL, Leipsic J, Gaur S, Seneviratne S, Ko BS, Ito H, Jensen JM, Mauri L, De Bruyne B, Bezerra H, et al; NXT Trial Study Group: Diagnostic performance of noninvasive fractional flow reserve derived from coronary computed tomography angiography in suspected coronary artery disease: The NXT trial (Analysis of Coronary Blood Flow Using CT Angiography: Next Steps). J Am Coll Cardiol 63: 1145-1155, 2014.

6. Menon BK, d'Esterre CD, Qazi EM, Almekhlafi M, Hahn L, Demchuk AM and Goyal M: Multiphase CT angiography: A new tool for the imaging triage of patients with acute ischemic stroke. Radiology 275: 510-520,2015.

7. Leipsic J, Abbara S, Achenbach S, Cury R, Earls JP, Mancini GJ, Nieman K, Pontone G and Raff GL: SCCT guidelines for the interpretation and reporting of coronary CT angiography: A report of the Society of Cardiovascular Computed Tomography Guidelines Committee. J Cardiovasc Comput Tomogr 8: 342-358, 2014.

8. Muhlestein JB, Lappé DL, Lima JA, Rosen BD, May HT, Knight S, Bluemke DA, Towner SR, Le V, Bair TL, et al: Effect of screening for coronary artery disease using $\mathrm{CT}$ angiography on mortality and cardiac events in high-risk patients with diabetes: The FACTOR-64 randomized clinical trial. JAMA 312: 2234-2243, 2014.

9. Taleb S, Tedgui A and Mallat Z: IL-17 and Th17 cells in atherosclerosis: Subtle and contextual roles. Arterioscler Thromb Vasc Biol 35: 258-264, 2015.

10. Durpès MC, Morin C, Paquin-Veillet J, Beland R, Paré M, Guimond MO, Rekhter M, King GL and Geraldes P: PKC- $\beta$ activation inhibits IL-18-binding protein causing endothelial dysfunction and diabetic atherosclerosis. Cardiovasc Res 106: 303-313, 2015.

11. Santos RD, Gidding SS, Hegele RA, Cuchel MA, Barter PJ, Watts GF, Baum SJ, Catapano AL, Chapman MJ, Defesche JC, et al; International Atherosclerosis Society Severe Familial Hypercholesterolemia Panel: Defining severe familial hypercholesterolaemia and the implications for clinical management: A consensus statement from the International Atherosclerosis Society Severe Familial Hypercholesterolemia Panel. Lancet Diabetes Endocrinol 4: 850-861, 2016.
12. Mita T, Katakami N, Yoshii H, Onuma T, Kaneto H, Osonoi T, Shiraiwa T, Kosugi K, Umayahara Y, Yamamoto T, et al; Collaborators on the Study of Preventive Effects of Alogliptin on Diabetic Atherosclerosis (SPEAD-A) Trial: Alogliptin, a dipeptidyl peptidase 4 inhibitor, prevents the progression of carotid atherosclerosis in patients with type 2 diabetes: The study of preventive effects of alogliptin on diabetic atherosclerosis (SPEAD-A). Diabetes Care 39: 139-148, 2016.

13. Abbas A, Gregersen I, Holm S, Daissormont I, Bjerkeli V, Krohg-Sørensen K, Skagen KR, Dahl TB, Russell D, Almås T, et al: Interleukin 23 levels are increased in carotid atherosclerosis: Possible role for the interleukin 23/interleukin 17 axis. Stroke 46: 793-799, 2015.

14. Tesche C, De Cecco CN, Caruso D, Baumann S, Renker M, Mangold S, Dyer KT, Varga-Szemes A, Baquet M, Jochheim D, et al: Coronary CT angiography derived morphological and functional quantitative plaque markers correlated with invasive fractional flow reserve for detecting hemodynamically significant stenosis. J Cardiovasc Comput Tomogr 10: 199-206, 2016.

15. Park HB, Heo R, ó Hartaigh B, Cho I, Gransar H, Nakazato R, Leipsic J, Mancini GB, Koo BK, Otake H, et al: Atherosclerotic plaque characteristics by $\mathrm{CT}$ angiography identify coronary lesions that cause ischemia: A direct comparison to fractional flow reserve. JACC Cardiovasc Imaging 8: 1-10, 2015.

16. Dalmas E, Venteclef N, Caer C, Poitou C, Cremer I, Aron-Wisnewsky J, Lacroix-Desmazes S, Bayry J, Kaveri SV, Clément K, et al: T cell-derived IL-22 amplifies IL-1 $\beta$-driven inflammation in human adipose tissue: Relevance to obesity and type 2 diabetes. Diabetes 63: 1966-1977, 2014.

17. Ryu H and Chung Y: Regulation of IL-17 in atherosclerosis and related autoimmunity. Cytokine 74: 219-227, 2015.

18. Yamagami H, Kitagawa K, Hoshi T, Furukado S, Hougaku H, Nagai Y and Hori M: Associations of serum IL-18 levels with carotid intima-media thickness. Arterioscler Thromb Vasc Biol 25: 1458-1462, 2005.

19. Durpès MC, Morin C, Paquin-Veillet J, Beland R, Paré M, Guimond MO, Rekhter M, King GL and Geraldes P: PKC- $\beta$ activation inhibits IL-18-binding protein causing endothelial dysfunction and diabetic atherosclerosis. Cardiovasc Res 106: 303-313, 2015.

20. Banoth B and Sutterwala FS: Confounding role of tumor necrosis factor in cryopyrin-associated periodic syndromes. J Clin Invest 127: 4235-4237, 2017.

21. Lee JS, Tato CM, Joyce-Shaikh B, Gulen MF, Cayatte C, Chen Y, Blumenschein WM, Judo M, Ayanoglu G, McClanahan TK, et al: Interleukin-23-independent IL-17 production regulates intestinal epithelial permeability. Immunity 43: 727-738, 2015.

22. Plée J, Le Jan S, Giustiniani J, Barbe C, Joly P, Bedane C, Vabres P, Truchetet F, Aubin F, Antonicelli F, et al: Integrating longitudinal serum IL-17 and IL-23 follow-up, along with autoantibodies variation, contributes to predict bullous pemphigoid outcome. Sci Rep 5: 18001, 2015

23. Xu C, Hao K, Yu L and Zhang X: Serum interleukin-17 as a diagnostic and prognostic marker for non-small cell lung cancer. Biomarkers 19: 287-290, 2014.

24. Takahara T, Shimizu M, Nakagishi Y, Kinjo N and Yachie A: Serum IL-18 as a potential specific marker for differentiating systemic juvenile idiopathic arthritis from incomplete Kawasaki disease. Rheumatol Int 35: 81-84, 2015.

25. Markus HS, Hayter E, Levi C, Feldman A, Venables G and Norris J; CADISS trial investigators: Antiplatelet treatment compared with anticoagulation treatment for cervical artery dissection (CADISS): A randomised trial. Lancet Neurol 14: 361-367, 2015.

26. Marnat G, Mourand I, Eker O, Machi P, Arquizan C, Riquelme C, Ayrignac X, Bonafé A and Costalat V: Endovascular management of tandem occlusion stroke related to internal carotid artery dissection using a distal to proximal approach: Insight from the RECOST study. AJNR Am J Neuroradiol 37: 1281-1288, 2016. International (CC BY-NC-ND 4.0) License. 